\title{
Alejandro Fielbaum S. Los bordes de la letra. Ensayos sobre teoría literaria
} latinoamericana en clave cosmopolita. Leiden: Almenara 2017, 329 pp. ISBN: 978-94-92260-18-5.

Antes que nada, agradecer al autor. El lector agradece que en el inicio mismo del libro, en la primera página nomás, aparezca una cita de Don DeLillo, y no varias, una tras otra como se acostumbra en la actualidad, de Slavoj Žižek, de Judith Butler (los cuales, por cierto, aparecen después), o de quien esté de moda en estos días de posdata, tal cual se hace para prolongar la primavera del lugar común a la que los estudios académicos nos tienen acostumbrados. Basta ver el rico archivo de esta duradera y prestigiosa revista para corroborar, a la manera de los índices bursátiles de Wall Street, las alzas y bajas que ha sufrido el mundillo de la crítica literaria latinoamericana a lo largo de las épocas, con sus muletillas y sus registros terminológicos en boga que van y vienen, pero que tarde o temprano terminan yéndose para siempre. Hoy sí, y mañana nadie se acuerda. En la colección de reseñas publicadas en la Revista Iberoamericana está enmarcada la historia de las modas críticas que han ido fagocitándose unas a otras. $\mathrm{Y}$ ese primer acierto mencionado no es el único de los varios de este volumen, cuyo registro formal muestra una encomiable amabilidad con el pensamiento. Otra rareza; es un libro académico bien escrito. La respiración de su sintaxis carece de altibajos. La lectura no lleva más de una semana, mismo tiempo casi que la relectura.

Según su nombre lo anticipa, este es un libro de ensayos ("los textos que aquí compilamos"), todos ellos aunados por afinidades teóricas y porque los textos y autores analizados provienen de un lugar comunicante en la geografía de la imaginación. Se trata, pues -y recurro a la generalización, dadas las circunstancias- de una invitación a la revisión y a la relectura; a releer entre líneas algunos pasajes del canon literario hispanoamericano en constante vías de desarrollo, auspiciando visitas tanto en flashback como en fast-forward. En el antes y el después reside aquello sobre lo que se quiere pensar. En este rubro resulta imperioso empezar de nuevo, en todo caso, retomar a partir de intuiciones recientes lo que aún no ha comenzado. Dice el autor en la primera sección: "Un libro que busque indagar en cierta tradición teórica, como lo es toda tradición, desplegada en un lugar de carácter múltiple, como lo es todo lugar, ha de partir preguntándose por las múltiples relaciones entre tradiciones teóricas y lugares". Quizá en su próximo libro Fielbaum S. podría abordar la cuestión respecto a cómo reflexionar sobre ideas y actos de la escritura a partir de "otras formas" organizadas de escribir, dentro y fuera del método, tal como los cambios radicales de los días actuales lo exigen y según la noción generalizada de "época” invita a entenderlos.

El libro visita varios temas sin someterse a la comodidad de las expectativas. La unidad que otorga una blindada coherencia al volumen proviene de lo discontinuo, de 
la intencional interrupción de la experiencia de continuidad de ideas sobre lo mismo. Hoy en día la crítica literaria latinoamericana no puede hacer sino eso. Me refiero a la crítica que va en pro del descubrimiento, no la que recurre a un fárrago de ideas ajenas y aparatos teóricos en boga y que a esta altura luce agotada. Hablo de la crítica que ayuda a encontrarle nuevas entradas a un texto, sobre todo aquellos que esperan ser interpelados a partir de perspectivas que en apariencia podrían parecer irrelevantes. Cabe también preguntarse, porque el libro, a la manera de archipiélago de ideas así lo permite, si tiene sentido seguir hablando de una unidad continental, y preguntarse de paso si la ilusión por un contenido de discursos literarios en apariencia comunicantes no será falaz. Por ejemplo, ¿convendrá seguir leyendo a Martí y Rodó desde el lugar de la interpretación hermenéutica o ideológica? ¿No sería mejor pasar de la deconstrucción a la demolición, dándole cabida a las nociones de Maurice Blanchot o Jean-Luc Nancy, entre otros, respecto a la poética del texto construida en base a los momentos en que el lenguaje solo tiene aspiración lírica? Ese reacomodo sería el paso previo a un rastreo inédito de las prácticas de innovación, en las cuales, ahí sí, se verifican "contenidos críticos", la amalgama de lo inexpresable.

De la misma forma que pasa con los discos, en los cuales hay canciones mejores que otras, también aquí el lector encuentra ensayos que, por escritura y por aporte de ideas no consideradas sobre los textos y autores, resultan más atractivos que los restantes. Me quedo con dos, favoritos por invitar a la discrepancia: "Los milagros de la literatura. El feminismo de la compensación de Carlos Vaz Ferreira ante la poesía de Delmira Agustini" y "Funes: civilización y barbarie". El reseñista se siente bien cuando entra en desacuerdo con el autor, sabiendo que las ideas presentadas por este no son producto de la improvisación. Es solo cuestión de ver lo mismo de manera diferente. En el primero de los mencionados afirma: "Es claro que la crítica de Herrera y Reissig resulta limitada en términos teóricos para comprender la situación que critica" (p.170). El comentario cae en el manido estereotipo académico de creer que toda argumentación es limitada si no viene acompañada de "términos teóricos". Son este tipo de afirmación muy a la ligera la que en determinados pasajes le quita agudeza y riesgo al volumen.

Por otra parte, en la misma página recurre a un comentario de Beatriz Sarlo que afirma que Agustini y Alfonsi Storni instalan "un nuevo repertorio temático en el Río de la Plata, a través de una poesía que reivindica la diferencia sexual". Conviene acotar que esta idea es más vieja que el hilo negro, por lo tanto resulta innecesario recurrir a Sarlo para validarla, salvo que Fielbaum S. haya querido decir que él es lector de los temas del poema y no del poema en sí, lo que este implica como maquinaria de escritura y acosos a la estructura, a la lógica del orden sintáctico. Lo que va para otros, también toca a este libro: ¿Es necesario citar a Derrida para decir que la tierra es redonda o que según Heidegger está lloviendo? Tres de los más innovadores ensayistas que dio la literatura, Montaigne, William Hazlitt y Robert Louis Stevenson, eran intencionalmente a-teóricos y sin embargo, en todo lo que no quisieron demostrar en "términos teóricos" 
impusieron una certeza y una credibilidad, no siempre compatible, de visión. En la misma línea están los comentarios de Herrera y Reissig citados por el autor.

Más allá de los comentarios que puedan resultar obvios por ser ya conocidos, y de estar incompleta la bibliografía consultada sobre algunos de los autores estudiados (la de Delmira Agustini, por ejemplo) Los bordes de la letra. Ensayos sobre teoría literaria latinoamericana en clave cosmopolita es un libro disfrutable. Sus logros están asociados a esos momentos claves de la discusión, cuando el autor no exhibe dependencia con las modas críticas y los clisés terminológicos que agobian a los estudios literarios académicos. Cuando Fielbaum S. se anima a mirar por su propio periscopio, descubre perspectivas no consideradas, tanto de los textos como de los autores estudiados. Ahí están sus mayores aciertos, incluso aunque pueda parecer que se equivoca.

Eduardo Espina

Texas A\&M University

Felipe Gómez Gutiérrez y María del Carmen Saldarriaga, editores. Evelio Rosero y los ciclos de la creación literaria. Bogotá: Editorial Pontificia Universidad Javeriana, 2017. 272 pp. ISBN: 978-9-5878-1063-9.

A medio camino entre los escritores muy conocidos y los perfectos desconocidos, son muchos los autores colombianos que no han tenido la suerte que tiene Rosero de contar con un compendio de artículos sobre su obra tan dedicado y abarcante como este. Su eje temático, como lo indica el título, es la comprobación de que hay elementos constantes a lo largo de una obra extensa y heterogénea. Sea en la novela histórica, en la poesía, en el teatro, o incluso en la literatura infantil y juvenil, Rosero tiene un estilo y una temática recurrente que los ensayos reunidos en este volumen se proponen desentrañar. Más que un autor repetitivo, se trataría pues de un autor que reflexiona a través de cierta repetición.

De manera poco convencional, el libro empieza con una entrevista inédita a Rosero, a quienes los editores conceden no la última, sino "la primera palabra" (27). En la entrevista, el escritor nariñense nacido en Bogotá se declara eminentemente narrador, refiriéndose a su dramaturgia y lírica como obra menor (30). Como es de esperar, el libro se plantea a contrapelo de ese tipo de pronunciamiento. Los doce ensayos del

$111 \frac{\text { Revista Iberoamericana, Vol. LXXXV, Núm. 268, Julio-Septiembre 2019, } 1075-1115}{\text { ISSN 0034-9631 (Impreso) }}$ 